\title{
The effects of pulmonary diseases on histologic types of lung cancer in both sexes: a population-based study in Taiwan
}

Jing-Yang Huang ${ }^{1}$, Zhi-Hong Jian ${ }^{1}$, Oswald Ndi Nfor ${ }^{1}$, Wen-Yuan Ku' ${ }^{1}$, Pei-Chieh Ko' ${ }^{1}$ Chia-Chi Lung ${ }^{1,2}$, Chien-Chang Ho ${ }^{3}$, Hui-Hsien Pan ${ }^{4,5}$, Chieh-Ying Huang ${ }^{6}$, Yu-Chiu Liang ${ }^{7}$ and Yung-Po Liaw ${ }^{1,2^{*}}$

\begin{abstract}
Background: The associations between pulmonary diseases (asthma, chronic obstructive pulmonary disease [COPD], and tuberculosis [TB]) and subsequent lung cancer risk have been reported, but few studies have investigated the association with different histologic types of lung cancer.

Methods: Patients newly diagnosed with lung cancer from 2004 to 2008 were identified from the National Health Insurance Research Database in Taiwan. Histologic types of lung cancer were further confirmed using the Taiwan Cancer Registry Database. Cox proportional hazards regression was used to calculate the hazard ratio (HR) of asthma, COPD, and TB and to estimate the risk of specific types of lung cancer.

Results: During the study period, 32,759 cases of lung cancer were identified from 15,219,024 insurants aged 20 years and older. In men and women, the adjusted HR estimates of squamous cell carcinoma were respectively 1.37 (95\% confidence interval $[\mathrm{Cl}], 1.21-1.54)$ and $2.10(95 \% \mathrm{Cl}, 1.36-3.23)$ for $\mathrm{TB}, 1.52(95 \% \mathrm{Cl}, 1.42-1.64)$ and 1.50 (95\% Cl, 1.21-1.85) for asthma, and $1.66(95 \% \mathrm{Cl}, 1.56-1.76)$ and $1.44(95 \% \mathrm{Cl}, 1.19-1.74)$ for COPD. Similarly, the adjusted $\mathrm{HR}$ estimates of adenocarcinoma were respectively 1.33 (95\% Cl, 1.19-1.50) and 1.86 (95 \% Cl, 1.57-2.19) for TB, $1.13(95 \% \mathrm{Cl}, 1.05-1.21)$ and 1.18 (95 \% Cl, 1.09-1.28) for asthma, and 1.50 (95\% Cl, 1.42$1.59)$ and $1.33(95 \% \mathrm{Cl}, 1.25-1.42)$ for COPD. The HRs of small cell carcinoma were respectively $1.24(95 \% \mathrm{Cl}, 1.01-1.52)$ and $2.23(95 \% \mathrm{Cl}, 1.17-4.25)$ for TB, $1.51(95 \% \mathrm{Cl}, 1.35-1.69)$ and $1.63(95 \% \mathrm{Cl}, 1.16-2.27)$ for asthma, and $1.39(95 \% \mathrm{Cl}$, $1.26-1.53)$ and $1.78(95 \% \mathrm{Cl}, 1.33-2.39)$ for COPD.
\end{abstract}

Conclusions: Asthma, COPD, and TB were associated with an increased risk of all major subtypes of lung cancer. The risk was the highest among women with $\mathrm{TB}$.

Keywords: Asthma, Chronic obstructive pulmonary disease, Lung adenocarcinoma, Small cell carcinoma, Squamous cell carcinoma, Tuberculosis

\section{Background}

Lung cancer is the second leading diseases contributing to years of life lost because of premature mortality [1]. Among histologic types of lung cancer, adenocarcinoma is the most common subtype in Asians but not in Europeans $[2,3]$. Typical risk factors for lung cancer include smoking

\footnotetext{
* Correspondence: Liawyp@csmu.edu.tw

'Department of Public Health and Institute of Public Health, Chung Shan Medical University, No. 110, Sec. 1 Jianguo N. Rd., Taichung City 40201, Taiwan

2Department of Family and Community Medicine, Chung Shan Medical University Hospital, 40201 Taichung City, Taiwan

Full list of author information is available at the end of the article
}

and exposure to arsenic, chromium, radon, or air pollution $[4,5]$. Smoking is the major risk factor for lung cancer, particularly squamous cell carcinoma (SqCC) [6]. However, a previous study demonstrated that most Taiwanese women with lung cancer are non-smokers [7]. A vast majority of smokers do not seem to develop lung cancer. Although smoking is a potential risk factor, other factors may also be linked to the increased risk of lung cancer.

Recent studies have concluded that chronic inflammation may be linked to lung carcinogenesis [8]. Among intrinsic pulmonary diseases, chronic obstructive pulmonary

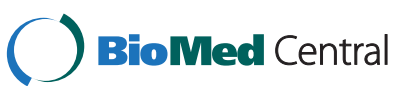

(c) 2015 Huang et al. Open Access This article is distributed under the terms of the Creative Commons Attribution 4.0 International License (http://creativecommons.org/licenses/by/4.0/), which permits unrestricted use, distribution, and reproduction in any medium, provided you give appropriate credit to the original author(s) and the source, provide a link to the Creative Commons license, and indicate if changes were made. The Creative Commons Public Domain Dedication waiver (http://creativecommons.org/publicdomain/zero/1.0/) applies to the data made available in this article, unless otherwise stated. 
disease (COPD) [9, 10], asthma [11], and tuberculosis (TB) [12] are associated with lung cancer. Smokers with COPD have a higher risk of SqCC [13, 14]. Asthma is associated with an increased risk of $\mathrm{SqCC}$ and small cell carcinoma (SmCC) but is weakly associated with adenocarcinoma $[15,16]$. TB is also associated with an increased risk of SqCC and adenocarcinoma but not SmCC [17]. An association between TB and lung adenocarcinoma has been reported in non-westernized countries [18]. Furthermore, the association of lung cancer with diabetes [19] and dyslipidemia [20-22] has been reported. Data on pulmonary diseases and specific histologic types of lung cancer are considerable limited in Taiwan.

For a detailed evaluation of the relationship between pulmonary diseases and histologic types of lung cancer, a population-based cohort study is highly desirable. However, few such studies have been conducted. This study assessed whether pulmonary diseases are associated with an increased risk of specific types of lung cancer.

\section{Methods \\ Database}

The National Health Insurance Research Database (NHIRD) contains enrollment files, claims data, catastrophic illness files, and treatment registries. The national health insurance program covers more than $99 \%$ of the population of Taiwan. The NHIRD is one of the largest administrative health care databases that is broadly used in academic studies [23-25]. This study used the linked databases of the NHIRD, Taiwan Cancer Registry Database (TCRD), and National Death Registry Database (NDRD) with the permission of the Department of Statistics, Ministry of Health and Welfare of Taiwan. The source data was encrypted and the data extracted was anonymous. This study was approved by the Institutional Review Board of the Chung-Shan Medical University Hospital, Taiwan.

\section{Identification of Patients With Lung Cancer}

In this study, 17,859,318 residents aged 20 years and older were initially enrolled. We excluded patients diagnosed with lung cancer before $2003(n=39,623)$ and those with incomplete information on sex $(n=2,600,565)$, registry data $(n=5)$, and death $(n=101)$. Finally, $15,219,024$ patients (8,002,536 men and 7,216,488 women) were enrolled in this study. Patients newly diagnosed with lung cancer in 2004 were followed up until death, loss to follow-up, or the study end in 2008. Lung cancer was identified using the International Classification of Diseases, Ninth Revision, Clinical Modification (ICD-9-CM) code 162.

Furthermore, histologic types of lung cancer were confirmed using the TCRD. The registry contains data on cancer types, initial tumor stages, and histology. Lung cancer was identified using the ICD-9-CM code 162 or ICD 10 codes C34.0, C34.1, C34.2, C34.3, C34.8, and C34.9 in the TCRD. Morphological diagnoses were determined using the ninth revision of the International Classification of Diseases for Oncology (ICD-O) on the basis of the following ICD-O codes: 80522, 80523, 80702, 80703, 80713, 80723, 80733, 80743, 80763, 80823, 80833, and 80843 for lung SqCC; 80503, 81402, $81403,81413,81433,82113,82503,82513,82523$, $82553,82603,83103,83233,84603,84803,84813$, 84903, and 85003 for adenocarcinoma; 80023, 80412, 80413, 80423, 80433, 80453, and 94733 for SmCC; and 80123, 80143, 80203, 80213, 80303, and 80313 for large cell carcinoma.

The linked databases were used to retrieve information on the age of lung cancer diagnosis, follow-up time (in person-years), and survival time and to minimize potentially unconfirmed cancer diagnoses.

\section{Variables of Exposure}

Baseline variables included age, sex, urbanization level, geographical area, low income, and comorbidities. To reduce bias, the diagnoses of pulmonary diseases and comorbidities were confirmed by more than two outpatient visits or one admission between 2001 and 2003. Pulmonary diseases and comorbidities were defined using the following ICD-9-CM codes: asthma (493), COPD (490, 491, 492, 494, and 496), TB (010 012, and137.0), chronic kidney disease (585 and 586), type II diabetes mellitus (250, which excludes type I diabetes mellitus), and hyperlipidemia (272). Smoking, a major risk factor for lung cancer, COPD, and other cancer types are not available in the NHIRD [26, 27]; hence, this prevented direct adjustment for all possible confounders. However, smoking -related cancers such as lip, oral cavity, nasal cavity, pharynx, larynx, esophagus (ICD-9-CM codes: $140-150$ and 160-161), pancreas (ICD-9-CM code 157), kidney, and bladder cancers (ICD-9-CM codes 188 and 189) were adjusted [28].

\section{Statistical Analyses}

All statistical analyses were conducted using the SAS statistical package (Version 9.3; SAS Institute, Inc., Cary, $\mathrm{NC}$ ). The characteristics of the study population were compared using the chi-square test. A $\mathrm{p}$ value of $<0.05$ was statistically significant. To evaluate the effect of age, patients were classified according to sex and age (20-39, $40-49,50-59,60-69,70-79$, and $\geq 80$ years). All cities and towns were divided into three urbanization levels: low, medium, and high. The Cox proportional hazards regression model was used to estimate the hazard ratios (HRs) of histologic types of lung cancer while controlling 
Table 1 Characteristics of the Study Population

\begin{tabular}{|c|c|c|c|}
\hline & Lung cancer $(N=32759)$ & Non-lung cancer $(N=15186265)$ & $p$-value \\
\hline \multicolumn{4}{|l|}{ Lung diseases (\%) } \\
\hline Tuberculosis & $1052(3.2)$ & $110469(0.7)$ & $<0.001$ \\
\hline Asthma & $4380(13.4)$ & $747889(4.9)$ & $<0.001$ \\
\hline COPD & $7883(24.1)$ & $1201101(7.9)$ & $<0.001$ \\
\hline Sex (\%) & & & $<0.001$ \\
\hline Men & $22872(69.8)$ & $7979664(52.6)$ & \\
\hline Women & $9887(30.2)$ & 7206601 (47.4) & \\
\hline Age (years, \%) & & & $<0.001$ \\
\hline $20-39$ & $1049(3.2)$ & $7221512(47.6)$ & \\
\hline $40-49$ & $3580(10.9)$ & $3464916(22.8)$ & \\
\hline $50-59$ & $5937(18.1)$ & $2209547(14.6)$ & \\
\hline $60-69$ & $7374(22.5)$ & $1036090(6.8)$ & \\
\hline $70-79$ & $10544(32.2)$ & $823322(5.4)$ & \\
\hline$\geqq 80$ & $4275(13.1)$ & $430878(2.8)$ & \\
\hline Low income $(\%)^{a}$ & $889(2.7)$ & $245045(1.6)$ & $<0.001$ \\
\hline \multicolumn{4}{|l|}{ Comorbidities (\%) } \\
\hline Diabetes & $5680(17.3)$ & $1060714(7.0)$ & $<0.001$ \\
\hline Hyperlipidemia & $5988(18.3)$ & 1347931 (8.9) & $<0.001$ \\
\hline Chronic kidney disease & $961(2.9)$ & $149730(1.0)$ & $<0.001$ \\
\hline Smoking-related cancers ${ }^{\mathrm{b}}$ & $777(2.4)$ & $103201(0.7)$ & $<0.001$ \\
\hline Geographical area (\%) & & & $<0.001$ \\
\hline Taipei City & $9236(28.2)$ & $4851844(32.0)$ & \\
\hline North & $3920(12.0)$ & $1961790(12.9)$ & \\
\hline Central & $6393(19.5)$ & $2936377(19.3)$ & \\
\hline South & $6614(20.2)$ & $2366398(15.6)$ & \\
\hline Kaohsiung-Pingtung & $5489(16.8)$ & $2628117(17.3)$ & \\
\hline East & $1107(3.3)$ & $441739(2.9)$ & \\
\hline Urbanization (\%) & & & $<0.001$ \\
\hline High & $13889(42.4)$ & 7519048 (49.5) & \\
\hline Mid & $12338(37.7)$ & $5575331(36.7)$ & \\
\hline Low & $6532(19.9)$ & 2091866 (13.8) & \\
\hline Death in 2004-2008 (\%) & $27718(84.6)$ & $648922(4.3)$ & $<0.001$ \\
\hline $\begin{array}{l}\text { Follow-up time } \\
\text { (person-year) }\end{array}$ & 84505 & 73801819 & \\
\hline \multicolumn{4}{|l|}{ Histologic type (\%) } \\
\hline Squamous cell carcinoma & $6637(20.3)$ & & \\
\hline Adenocarcinoma & $15490(47.3)$ & & \\
\hline Small cell carcinoma & $3019(9.2)$ & & \\
\hline Large cell carcinoma & $240(0.7)$ & & \\
\hline Others & $7373(22.5)$ & & \\
\hline
\end{tabular}

Income is lower than the level required for charging premium

${ }^{\mathrm{b}}$ Smoking-related cancers included lip, oral cavity, nasal cavity, pharynx, larynx, and esophagus, pancreas, kidney and bladder cancers that were prior to a diagnosis of lung cancer

Abbreviations: $C O P D$, chronic obstructive pulmonary disease 
for age, geographical area, urbanization level, low income, and comorbidities.

\section{Results}

During the study period, 32,759 cases of lung cancer were identified. Of all patients diagnosed, $47.3 \%$ had adenocarcinoma (M: F, 8,778: 6,712), $20.3 \%$ had SqCC (5,877: 760), $9.2 \%$ had SmCC (2,751: 268), $0.7 \%$ had large cell carcinoma (183: 57 ), and $23.2 \%$ had other diseases (5,283: 2,090). The demographic characteristics and comorbidities of the study population are displayed in Table 1. Patients with lung cancer had higher rates of asthma, COPD, TB, hyperlipidemia, diabetes, chronic kidney disease, and smoking-related cancer than individuals without lung cancer did.

In Table 2, Cox regression analysis revealed a significantly high incidence of lung cancer in male patients with COPD ( $\mathrm{HR}, 1.56$; $95 \%$ confidence interval $[\mathrm{CI}]$, 1.51-1.61), asthma (HR, 1.36; $95 \% \mathrm{CI}, 1.30-1.41)$, TB (HR, 1.35; 95 \% CI, 1.26-1.44), low income (HR, 1.14; $95 \% \mathrm{CI}, 1.05-1.23$ ), hyperlipidemia (HR, 1.07; 95\%CI, 1.04-1.11), and smoking-related cancer (HR, 1.79; $95 \%$ CI, 1.68-1.90). The risk of lung cancer was high in female patients with TB (HR, 1.97; $95 \% \mathrm{CI}, 1.73-2.24)$, COPD (HR, 1.33; $95 \%$ CI, 1.26-1.41), asthma (HR, 1.26; $95 \% \mathrm{CI}, 1.18-1.34)$, low income (HR, 1.36; 95 \% CI,
1.20-1.54), hyperlipidemia (HR, 1.13; 95 \% CI, $1.07-$ 1.19), and smoking related cancer (HR, 2.28; $95 \% \mathrm{CI}$, 2.02-2.57).

Table 3 presents the adjusted HRs for SqCC stratified by sex. The incidence of $\mathrm{SqCC}$ was high in male patients with COPD (HR, 1.66; 95 \% CI, 1.56-1.76), asthma (HR, 1.52; 95 \% CI, 1.42-1.64), TB (HR, 1.37; 95 \% CI, 1.21-1.54), and smoking-related cancer (HR, 2.58; $95 \% \mathrm{CI}, 2.33-$ 2.86). The HRs of SqCC in women with $\mathrm{TB}$, asthma, COPD, and smoking-related cancer were 2.10 (95\% CI, 1.36-3.23), 1.50 (95 \% CI, 1.21-1.85), 1.44 (95 \% CI, 1.191.74), and 3.98 ( $95 \% \mathrm{CI}, 2.84-5.57)$, respectively.

Table 4 provides the HRs of adenocarcinoma stratified by sex. The risk of adenocarcinoma was high in male patients with COPD (HR, 1.50; 95 \% CI, 1.421.59), TB (HR, 1.33; 95 \% CI, 1.19-1.50), asthma (HR, 1.13; 95 \% CI, 1.05-1.21), hyperlipidemia (HR, 1.19; $95 \% \mathrm{CI}, 1.12-1.26)$, and smoking-related cancer (HR, 1.46; $95 \% \mathrm{CI}, 1.30-1.63)$. The HRs of adenocarcinoma in female patients with TB, COPD, asthma, hyperlipidemia, and smoking-related cancer were 1.86 (95 \% CI, 1.57-2.19), 1.33 (95 \% CI, 1.25-1.42), 1.18 (95\% CI, 1.09-1.28), 1.19 (95\% CI, 1.12-1.26), and 2.00 (95\% CI, 1.71-2.35), respectively.

Table 5 displays the adjusted HRs of SmCC stratified by sex. The risk of SmCC was high in male patients with

Table 2 Hazard Ratios and 95 \% Confidence Intervals of Lung Cancer Stratified by Sex

\begin{tabular}{|c|c|c|c|c|}
\hline & \multicolumn{2}{|l|}{ Male } & \multicolumn{2}{|l|}{ Female } \\
\hline & $\mathrm{HR}(95 \% \mathrm{Cl})$ & $P$ value & $\mathrm{HR}(95 \% \mathrm{Cl})$ & $P$ value \\
\hline \multicolumn{5}{|l|}{ Lung diseases } \\
\hline Tuberculosis & $1.35(1.26-1.44)$ & $<0.001$ & $1.97(1.73-2.24)$ & $<0.001$ \\
\hline Asthma & $1.36(1.30-1.41)$ & $<0.001$ & $1.26(1.18-1.34)$ & $<0.001$ \\
\hline COPD & $1.56(1.51-1.61)$ & $<0.001$ & $1.33(1.26-1.41)$ & $<0.001$ \\
\hline Low income ${ }^{a}$ & $1.14(1.05-1.23)$ & 0.001 & $1.36(1.20-1.54)$ & $<0.001$ \\
\hline \multicolumn{5}{|l|}{ Age group } \\
\hline $20-39$ & $0.14(0.13-0.16)$ & $<0.001$ & $0.15(0.14-0.17)$ & $<0.001$ \\
\hline $40-49$ & Reference & & Reference & \\
\hline $50-59$ & $2.80(2.65-2.96)$ & $<0.001$ & $2.17(2.03-2.31)$ & $<0.001$ \\
\hline $60-69$ & $7.30(6.93-7.69)$ & $<0.001$ & $4.35(4.07-4.65)$ & $<0.001$ \\
\hline $70-79$ & $12.70(12.08-13.34)$ & $<0.001$ & $6.70(6.26-7.16)$ & $<0.001$ \\
\hline$\geqq 80$ & $8.91(8.43-9.43)$ & $<0.001$ & $5.72(5.30-6.17)$ & $<0.001$ \\
\hline \multicolumn{5}{|l|}{ Comorbidities } \\
\hline Diabetes & $1.00(0.96-1.04)$ & 0.926 & $1.01(0.96-1.07)$ & 0.689 \\
\hline Hyperlipidemia & $1.07(1.04-1.11)$ & $<0.001$ & $1.13(1.07-1.19)$ & $<0.001$ \\
\hline Chronic kidney disease & $0.90(0.84-0.97)$ & 0.004 & $0.87(0.76-0.99)$ & 0.035 \\
\hline Smoking-related cancers ${ }^{b}$ & $1.79(1.68-1.90)$ & $<0.001$ & $2.28(2.02-2.57)$ & $<0.001$ \\
\hline
\end{tabular}

Adjustments were made to estimate HRs for all covariates (lung diseases, low income, age, comorbidities, urbanization and geographic area) ${ }^{\mathrm{a}}$ Income is lower than the level required for charging premium

${ }^{\mathrm{b}}$ Smoking-related cancers included lip, oral cavity, nasal cavity, pharynx, larynx, and esophagus, pancreas, kidney and bladder cancers that were prior to a diagnosis of lung cancer

Abbreviations: $\mathrm{Cl}$, confidence interval; $C O P D$, chronic obstructive pulmonary disease; $H R$, hazard ratio 
Table 3 Hazard Ratios and 95 \% Confidence Intervals of Squamous Cell Carcinoma Stratified by Sex

\begin{tabular}{|c|c|c|c|c|}
\hline & \multicolumn{2}{|l|}{ Male } & \multicolumn{2}{|l|}{ Female } \\
\hline & $\mathrm{HR}(95 \% \mathrm{Cl})$ & $P$ value & HR $(95 \%$ Cl) & $P$ value \\
\hline \multicolumn{5}{|l|}{ Lung diseases } \\
\hline Tuberculosis & $1.37(1.21-1.54)$ & $<0.001$ & $2.10(1.36-3.23)$ & $<0.001$ \\
\hline Asthma & $1.52(1.42-1.64)$ & $<0.001$ & $1.50(1.21-1.85)$ & $<0.001$ \\
\hline COPD & $1.66(1.56-1.76)$ & $<0.001$ & $1.44(1.19-1.74)$ & $<0.001$ \\
\hline Low income $e^{a}$ & $1.15(0.99-1.34)$ & 0.066 & $2.35(1.66-3.32)$ & $<0.001$ \\
\hline \multicolumn{5}{|l|}{ Age group } \\
\hline 20-39 & $0.12(0.09-0.15)$ & $<0.001$ & $0.14(0.09-0.20)$ & $<0.001$ \\
\hline $40-49$ & Reference & & Reference & \\
\hline $50-59$ & $3.59(3.16-4.08)$ & $<0.001$ & $2.05(1.62-2.59)$ & $<0.001$ \\
\hline $60-69$ & $12.38(10.98-13.95)$ & $<0.001$ & $4.47(3.54-5.65)$ & $<0.001$ \\
\hline 70-79 & $21.39(19.03-24.04)$ & $<0.001$ & $6.23(4.89-7.92)$ & $<0.001$ \\
\hline$\geqq 80$ & 13.36 (11.74-15.19) & $<0.001$ & $4.66(3.51-6.19)$ & $<0.001$ \\
\hline \multicolumn{5}{|l|}{ Comorbidities } \\
\hline Diabetes & $1.00(0.93-1.07)$ & 0.922 & $1.14(0.94-1.39)$ & 0.169 \\
\hline Hyperlipidemia & $0.98(0.92-1.06)$ & 0.668 & $0.97(0.80-1.17)$ & 0.717 \\
\hline Chronic kidney disease & $0.85(0.73-0.97)$ & 0.020 & $0.85(0.53-1.34)$ & 0.473 \\
\hline Smoking-related cancers ${ }^{\mathrm{b}}$ & $2.58(2.33-2.86)$ & $<0.001$ & $3.98(2.84-5.57)$ & $<0.001$ \\
\hline
\end{tabular}

Adjustments were made to estimate HRs for all covariates (lung diseases, low income, age, comorbidities, urbanization and geographic area)

ancome is lower than the level required for charging premium

${ }^{b}$ Smoking-related cancers included lip, oral cavity, nasal cavity, pharynx, larynx, and esophagus, pancreas, kidney and bladder cancers that were prior to a diagnosis of lung cancer

Abbreviations: $\mathrm{Cl}$, confidence interval; $C O P D$, chronic obstructive pulmonary disease; $H R$, hazard ratio

asthma (HR, 1.51; 95 \% CI, 1.35-1.69), COPD (HR, 1.39; 95 \% CI, 1.26-1.53), TB (HR, 1.24; 95 \% CI, 1.01-1.52), and smoking-related cancer (HR, 1.35; $95 \% \mathrm{CI}, 1.10-$ 1.66). The HRs of SmCC in women with TB, COPD, asthma, and smoking-related cancer were $2.23(95 \% \mathrm{CI}$, 1.17-4.25), 1.78 (95 \% CI, 1.33-2.39), 1.63 (95\% CI, $1.16-2.27$ ), and 3.71 (95\% CI, 2.12-6.49), respectively.

\section{Discussion}

This study demonstrated that male and female patients with TB, asthma, and COPD had increased risks of lung SqCC, adenocarcinoma, and SmCC. Determining risk factors for specific types of lung cancer can help physicians gain a detailed understanding of the etiology of lung cancer and therefore identify the high-risk population for screening. To the best of our knowledge, no study has investigated the association between pulmonary diseases and histologic types of lung cancer. According to the study results, heterogeneity was observed in the risk factors for lung cancer and the different histologic types in male and female patients.

A population-based, case-control study of female nonsmokers revealed an increased risk of lung cancer in patients with TB who were diagnosed before the age of 21 years [29]. The incidence rate ratio of lung cancer in the TB cohorts was 1.98 (95\%CI, 1.37-2.83) $2-4$ years after TB infection [12]. A hospital-based, case-control study involving interviews of 226 female nonsmokers with lung cancer and 279 controls demonstrated that TB increased the risk of lung cancer (odds ratio [OR], 4.7; $95 \%$ CI, 1.6-13.2) [30]. Yu et al. found an increased risk of lung cancer among patients with TB (HR, 3.32; $95 \%$ CI, 2.70-4.09), which was higher than that of COPD (HR, 2.30; 95 \% CI, 2.07-2.55) [28]. A systematic review identified a direct relationship between preexisting TB and lung cancer, particularly adenocarcinoma (relative risk [RR], 1.6; $95 \% \mathrm{CI}, 1.2-2.1$ ) [18]. A study conducted in Taiwan demonstrated that TB was an independent risk factor for SqCC, SmCC, and adenocarcinoma in men and women [6]. Such an association is particularly crucial in Taiwan, where the prevalence of TB is high $[31,32]$. Compared with asthma and COPD, TB appears to have a stronger association with lung cancer among women. Additional studies are necessary to assess the possible mechanisms of this association.

In this study, COPD was associated with the risk of the major types of lung cancer. Chronic airway inflammation is a major risk factor for COPD and is also associated with an increased risk of lung cancer [13]. A study involving the 22-year follow-up of 5,402 
Table 4 Hazard Ratios and 95 \% Confidence Intervals of Adenocarcinoma Stratified by Sex

\begin{tabular}{|c|c|c|c|c|}
\hline & \multicolumn{2}{|l|}{ Male } & \multirow[b]{2}{*}{ HR $(95 \% \mathrm{Cl})$} & \multirow[b]{2}{*}{$P$ value } \\
\hline & $\mathrm{HR}(95 \% \mathrm{Cl})$ & $P$ value & & \\
\hline \multicolumn{5}{|l|}{ Lung diseases } \\
\hline Tuberculosis & $1.33(1.19-1.50)$ & $<0.001$ & $1.86(1.57-2.19)$ & $<0.001$ \\
\hline Asthma & $1.13(1.05-1.21)$ & $<0.001$ & $1.18(1.09-1.28)$ & $<0.001$ \\
\hline COPD & $1.50(1.42-1.59)$ & $<0.001$ & $1.33(1.25-1.42)$ & $<0.001$ \\
\hline Low income $e^{a}$ & $1.07(0.94-1.22)$ & 0.322 & $1.18(1.00-1.39)$ & 0.055 \\
\hline \multicolumn{5}{|l|}{ Age group } \\
\hline $20-39$ & $0.15(0.13-0.17)$ & $<0.001$ & $0.15(0.13-0.17)$ & $<0.001$ \\
\hline $40-49$ & Reference & & Reference & \\
\hline $50-59$ & $2.45(2.27-2.64)$ & $<0.001$ & $2.17(2.01-2.34)$ & $<0.001$ \\
\hline $60-69$ & $5.23(4.85-5.63)$ & $<0.001$ & $4.10(3.80-4.44)$ & $<0.001$ \\
\hline $70-79$ & $8.15(7.59-8.76)$ & $<0.001$ & $5.93(5.46-6.43)$ & $<0.001$ \\
\hline$\geqq 80$ & $5.61(5.15-6.11)$ & $<0.001$ & $4.03(3.64-4.45)$ & $<0.001$ \\
\hline \multicolumn{5}{|l|}{ Comorbidities } \\
\hline Diabetes & $0.95(0.90-1.01)$ & 0.106 & $0.95(0.89-1.02)$ & 0.128 \\
\hline Hyperlipidemia & $1.19(1.12-1.26)$ & $<0.001$ & $1.19(1.12-1.26)$ & $<0.001$ \\
\hline Chronic kidney disease & $0.86(0.76-0.98)$ & 0.019 & $0.84(0.71-0.99)$ & 0.040 \\
\hline Smoking-related cancers ${ }^{\mathrm{b}}$ & $1.46(1.30-1.63)$ & $<0.001$ & $2.00(1.71-2.35)$ & $<0.001$ \\
\hline
\end{tabular}

Adjustments were made to estimate HRs for all covariates (lung diseases, low income, age, comorbidities, urbanization and geographic area)

ancome is lower than the level required for charging premium

${ }^{b}$ Smoking-related cancers included lip, oral cavity, nasal cavity, pharynx, larynx, and esophagus, pancreas, kidney and bladder cancers that were prior to a diagnosis of lung cancer

Abbreviations: $\mathrm{Cl}$, confidence interval; $C O P D$, chronic obstructive pulmonary disease; $H R$, hazard ratio

participants concluded that moderate-to-severe obstructive pulmonary disease was associated with a higher risk of incident lung cancer (HR, 2.8; 95 \% CI, 1.8-4.4) [33]. Denholm et al. found that chronic bronchitis and emphysema were positively associated with lung cancer after adjusting for other respiratory diseases and smoking (OR, 1.33; 95 \% CI, 1.20-1.48 for men; OR, 1.50; 95 \% CI, 1.21-1.87 for women) [34]. The prevalence of smoking is almost 10fold higher in Taiwanese men than that in women [35]. However, the smoking status of the study population was not available. This may be the reason for the observed differences between men and women. Chronic bronchitis and emphysema increased the risk of SqCC (HR, 1.54; $95 \%$ CI, 1.09-2.18) independent of smoking [36]. COPD also increased the risk of SqCC in smokers [13]. Pesch et al. performed a pooled analysis of case-control studies including 13,169 cases and 16,010 controls from Europe and Canada [37]. Their analysis demonstrated that adenocarcinoma was the most prevalent subtype in never-smokers and women. The ORs were elevated for exposure to cigarette smoke and were higher for SqCC and SmCC than for adenocarcinoma. Freedman et al. recruited 279,214 men and 184,623 women aged 50-71 years from eight states in the United States to evaluate whether women were more susceptible to lung cancer caused by cigarette smoking than men [38]. Their results illustrated that the HRs of adenocarcinoma, SmCC, and undifferentiated tumors were similar between men and women among ex-smokers and current smokers. However, among current smokers, the $\mathrm{HR}$ of $\mathrm{SqCC}$ in men was approximately 2 -fold higher than that in women.

This study also suggests that patients with asthma are at an increased risk of three histological types ( $\mathrm{SqCC}$, adenocarcinoma, and SmCC) of lung cancer. Asthma is one of the most common chronic airway diseases and affects 300 million people of all ages and ethnicities [39]. In Taiwan, the prevalence of asthma has increased to $11.9 \%$ [40]. Because asthma causes complex chronic airway inflammation, it has been hypothesized to lead to carcinogenesis [8]. Case-control studies have produced varied results for the association between asthma and lung cancer [41, 42]. In a Swedish cohort with a hospital-discharge diagnosis of asthma, the standardized incidence rate ratio of lung cancer was 1.51 in men $(95 \% \mathrm{CI}, 1.38-1.65)$ and 1.78 in women (95\% CI, 1.55-2.03), and the risk of histologic types of lung cancer was higher in patients with SqCC and SmCC [16]. In a meta-analysis, the RRs were 1.69 (95\% CI, 1.26-2.26) for SqCC, 1.71 (95 \% CI, 0.99-2.95) for SmCC, and 1.09 (95 \% CI, 0.88-1.36) for adenocarcinoma [15].

In this study, hyperlipidemia was also associated with an increased risk of adenocarcinoma. Hyperlipidemia is a component of metabolic syndrome and is associated 
Table 5 Hazard Ratios and 95 \% Confidence Intervals of Small Cell Carcinoma by Stratified by Sex

\begin{tabular}{|c|c|c|c|c|}
\hline & \multicolumn{2}{|l|}{ Male } & \multicolumn{2}{|l|}{ Female } \\
\hline & $\mathrm{HR}(95 \% \mathrm{Cl})$ & $P$ value & HR $(95 \%$ Cl) & $P$ value \\
\hline \multicolumn{5}{|l|}{ Lung diseases } \\
\hline Tuberculosis & $1.24(1.01-1.52)$ & 0.037 & $2.23(1.17-4.25)$ & 0.015 \\
\hline Asthma & $1.51(1.35-1.69)$ & $<0.001$ & $1.63(1.16-2.27)$ & 0.005 \\
\hline COPD & $1.39(1.26-1.53)$ & $<0.001$ & $1.78(1.33-2.39)$ & $<0.001$ \\
\hline Low income ${ }^{a}$ & $0.96(0.75-1.23)$ & 0.738 & $2.91(1.80-4.68)$ & $<0.001$ \\
\hline \multicolumn{5}{|l|}{ Age group } \\
\hline $20-39$ & $0.09(0.06-0.12)$ & $<0.001$ & $0.10(0.04-0.27)$ & $<0.001$ \\
\hline $40-49$ & Reference & & Reference & \\
\hline $50-59$ & $3.47(2.93-4.10)$ & $<0.001$ & $3.73(2.31-6.01)$ & $<0.001$ \\
\hline $60-69$ & $10.60(9.04-12.43)$ & $<0.001$ & $10.86(6.80-17.33)$ & $<0.001$ \\
\hline $70-79$ & $17.1(14.64-19.98)$ & $<0.001$ & $14.19(8.73-23.07)$ & $<0.001$ \\
\hline$\geqq 80$ & $9.61(8.03-11.49)$ & $<0.001$ & $14.97(8.97-24.97)$ & $<0.001$ \\
\hline \multicolumn{5}{|l|}{ Comorbidities } \\
\hline Diabetes & $1.07(0.96-1.18)$ & 0.226 & $1.24(0.92-1.69)$ & 0.162 \\
\hline Hyperlipidemia & $1.09(0.98-1.21)$ & 0.100 & $0.84(0.61-1.15)$ & 0.264 \\
\hline Chronic kidney disease & $0.70(0.55-0.89)$ & 0.003 & $0.90(0.44-1.84)$ & 0.774 \\
\hline Smoking-related cancers ${ }^{\mathrm{b}}$ & $1.35(1.10-1.66)$ & 0.004 & $3.71(2.12-6.49)$ & $<0.001$ \\
\hline
\end{tabular}

Adjustments were made to estimate HRs for all covariates (lung diseases, low income, age, comorbidities, urbanization and geographic area)

ancome is lower than the level required for charging premium

${ }^{b}$ Smoking-related cancers included lip, oral cavity, nasal cavity, pharynx, larynx, and esophagus, pancreas, kidney and bladder cancers that were prior to a diagnosis of lung cancer

Abbreviations: $C l$, confidence interval; $C O P D$, chronic obstructive pulmonary disease; $H R$, hazard ratio

with insulin resistance [43]. Hyperinsulinemia, hyperglycemia, and chronic inflammation play a vital role in the neoplastic process [44]. High serum triglyceride concentrations are associated with an increased risk of lung cancer (fourth vs first quartile: HR, 1.94; 95 \% CI, 1.472.54) [22]. Additional studies are required to assess the association between hyperlipidemia and adenocarcinoma.

Evaluating the temporal relationship between pulmonary diseases and subsequent lung cancer in case-control studies is difficult. Previous studies might have yielded inconclusive results because they focused mainly on the high-risk populations of heavy smokers. This study has several strengths. First, our data were retrieved from combined databases (NHIRD, TCRD and NDRD) that included all residents; hence, recall and selection bias was minimized. Second, the histologic type of lung cancer was confirmed using the TCRD. Nevertheless, our study has some limitations. First, the NHIRD does not contain detailed clinical data and information on lifestyle-related factors such as smoking, obesity, physical inactivity, dietary habits, and family history, which are closely associated with lung cancer. Smoking is a major confounding factor of lung cancer. Biases were minimized by adjusting for COPD and smoking-related cancer. Second, patients with asthma, COPD, and TB may have used medications that may have complicated their conditions. This study did not evaluate the effects of drugs.

\section{Conclusions}

This study demonstrated that asthma, COPD, and TB were associated with increased risks of all major subtypes of lung cancer. The risk was the highest among women with TB.

\section{Abbreviations \\ Cl: Confidence interval; COPD: Chronic obstructive pulmonary disease; HR: Hazard ratio; ICD-9-CM: International Classification of Diseases, Ninth Revision, Clinical Modification code; ICD-O: International Classification of Diseases for Oncology; NDRD: National Death Registry Database; NHIRD: National Health Insurance Research Database; OR: Odds ratio; RR: Relative risk; SmCC: Small cell carcinoma; SqCC: Squamous cell carcinoma; TB: Pulmonary tuberculosis; TCRD: Taiwan Cancer Registry Database.}

\section{Competing Interests}

The authors declare that they have no competing interests.

\section{Author Contributions}

$J \mathrm{YH}, \mathrm{ZHJ}$, and YPL conceived and designed the study. JYH, PCK, and CCL performed the experiments. ZHJ, JYH, WYK, CCH, and HHP analyzed the data. $\mathrm{CYH}, \mathrm{YCL}$, and $\mathrm{CCL}$ contributed analysis tools. ONN, CCL, WYK, and CCH provided critical inputs on design, analysis, and interpretation of the study. All the authors had access to the data. All authors read and approved the final manuscript as submitted. 


\section{Acknowledgements}

We are grateful to the Department of Statistics, Ministry of Health and Welfare of Taiwan for granting us access to the NHIRD, Cancer Register Files, and National Death Files. The descriptions or conclusions herein do not represent the viewpoint of the Department of Statistics, Ministry of Health and Welfare of Taiwan.

\section{Author details}

'Department of Public Health and Institute of Public Health, Chung Shan Medical University, No. 110, Sec. 1 Jianguo N. Rd., Taichung City 40201, Taiwan. ${ }^{2}$ Department of Family and Community Medicine, Chung Shan Medical University Hospital, 40201 Taichung City, Taiwan. ${ }^{3}$ Department of Physical Education, Fu Jen Catholic University, New Taipei City, Taiwan. ${ }^{4}$ School of Medicine, Chung Shan Medical University, Taichung City, Taiwan. ${ }^{5}$ Department of Pediatrics, Chung Shan Medical University Hospital, Taichung City, Taiwan. ${ }^{6}$ Department of Chemical Technology, Songshan High School of Agriculture and Industry, Taipei City, Taiwan. ${ }^{7}$ College of Humanities and Social Sciences, Taipei Medical University, Taipei City, Taiwan.

Received: 25 July 2014 Accepted: 23 October 2015

Published online: 02 November 2015

\section{References}

1. US Burden of Disease Collaborators. The state of US health, 1990-2010: burden of diseases, injuries, and risk factors. JAMA. 2013;310:591-608.

2. Yang SC, Lai WW, Su WC, Wu SY, Chen HH, Wu YL, et al. Estimating the lifelong health impact and financial burdens of different types of lung cancer. BMC Cancer. 2013;13:579.

3. Wang BY, Huang JY, Cheng CY, Lin CH, Ko J, Liaw YP. Lung cancer and prognosis in taiwan: a population-based cancer registry. J Thorac Oncol. 2013:8:1128-35.

4. Ahsan $\mathrm{H}$, Thomas DC. Lung cancer etiology: independent and joint effects of genetics, tobacco, and arsenic. JAMA. 2004;292:3026-9.

5. $\quad$ Alberg AJ, Samet JM. Epidemiology of lung cancer. Chest. 2003;123 (1 Suppl):21S-49S

6. Le CH, Ko YC, Cheng LS, Lin YC, Lin HJ, Huang MS, et al. The heterogeneity in risk factors of lung cancer and the difference of histologic distribution between genders in Taiwan. Cancer Causes Control. 2001;12:289-300.

7. Chen KY, Hsiao CF, Chang GC, Tsai YH, Su WC, Perng RP, et al. Hormone replacement therapy and lung cancer risk in Chinese. Cancer. 2007;110:1768-75.

8. Ballaz S, Mulshine JL. The potential contributions of chronic inflammation to lung carcinogenesis. Clin Lung Cancer. 2003;5:46-62.

9. Young RP, Hopkins RJ, Christmas T, Black PN, Metcalf P, Gamble GD. COPD prevalence is increased in lung cancer, independent of age, sex and smoking history. Eur Respir J. 2009;34:380-6.

10. Thomsen $M$, Ingebrigtsen TS, Marott $J$, Dahl M, Lange P, Vestbo J, et al. Inflammatory biomarkers and exacerbations in chronic obstructive pulmonary disease. JAMA. 2013;309:2353-61.

11. Santillan AA, Camargo Jr CA, Colditz GA. A meta-analysis of asthma and risk of lung cancer (United States). Cancer Causes Control. 2003;14:327-34.

12. Wu CY, Hu HY, Pu CY, Huang N, Shen HC, Li CP, et al. Pulmonary tuberculosis increases the risk of lung cancer: a population-based cohort study. Cancer. 2011;117:618-24.

13. Wang ZL. Association between chronic obstructive pulmonary disease and lung cancer: the missing link. Chin Med J. 2013;126:154-65.

14. Papi A, Casoni G, Caramori G, Guzzinati I, Boschetto P, Ravenna F, et al. COPD increases the risk of squamous histological subtype in smokers who develop non-small cell lung carcinoma. Thorax. 2004;59:679-81.

15. Rosenberger A, Bickeboller H, McCormack V, Brenner DR, Duell EJ, Tjonneland A, et al. Asthma and lung cancer risk: a systematic investigation by the International Lung Cancer Consortium. Carcinogenesis. 2012;33:587-97.

16. Boffetta P, Ye W, Boman G, Nyren. Lung cancer risk in a population-based cohort of patients hospitalized for asthma in Sweden. Eur Respir J. 2002;19:127-33.

17. Park SK, Cho LY, Yang JJ, Park B, Chang SH, Lee KS, et al. Lung cancer risk and cigarette smoking, lung tuberculosis according to histologic type and gender in a population based case-control study. Lung Cancer. 2010;68:20-6.

18. Liang HY, Li XL, Yu XS, Guan P, Yin ZH, He QC, et al. Facts and fiction of the relationship between preexisting tuberculosis and lung cancer risk: a systematic review. Int J Cancer. 2009;125:2936-44.
19. Lee MY, Lin KD, Hsiao PJ, Shin SJ. The association of diabetes mellitus with liver, colon, lung, and prostate cancer is independent of hypertension, hyperlipidemia, and gout in Taiwanese patients. Metabolism. 2012;61:242-9.

20. Kucharska-Newton AM, Rosamond WD, Schroeder JC, McNeill AM, Coresh J, Folsom AR. HDL-cholesterol and the incidence of lung cancer in the Atherosclerosis Risk in Communities (ARIC) study. Lung Cancer. 2008:61:292-300

21. Kitahara CM. Berrington de Gonzalez A, Freedman ND, Huxley R, Mok Y, Jee $\mathrm{SH}$, et al. Total cholesterol and cancer risk in a large prospective study in Korea. J Clin Oncol. 2011;29:1592-8.

22. Ulmer H, Borena W, Rapp K, Klenk J, Strasak A, Diem G, et al. Serum triglyceride concentrations and cancer risk in a large cohort study in Austria. Br J Cancer. 2009:101:1202-6.

23. Pan HH, Chen $\mathrm{CT}$, Sun HL, Ku MS, Liao PF, Lu KH, et al. Comparison of the effects of air pollution on outpatient and inpatient visits for asthma: a population-based study in taiwan. PLoS One. 2014;9, e96190.

24. Shen TC, Chung WS, Lin CL, Wei CC, Chen CH, Chen HJ, et al. Does Chronic Obstructive Pulmonary Disease with or without Type 2 Diabetes Mellitus Influence the Risk of Lung Cancer? Result from a Population-Based Cohort Study. PLoS One. 2014;9:e98290.

25. Wang KC, Chang WH, Lee WL, Huang N, Huang HY, Yen MS, et al. An increased risk of epithelial ovarian cancer in Taiwanese women with a new surgico-pathological diagnosis of endometriosis. BMC Cancer. 2014;14:831.

26. Yang L, Lu X, Deng J, Zhou Y, Huang D, Qiu F, et al. Risk factors shared by COPD and lung cancer and mediation effect of COPD: two center case-control studies. Cancer Causes Control. 2015;26:11-24.

27. Park S, Jee SH, Shin HR, Park EH, Shin A, Jung KW, et al. Attributable fraction of tobacco smoking on cancer using population-based nationwide cancer incidence and mortality data in Korea. BMC Cancer. 2014;14:406.

28. Yu YH, Liao CC, Hsu WH, Chen HJ, Liao WC, Muo CH, et al. Increased lung cancer risk among patients with pulmonary tuberculosis: a population cohort study. J Thorac Oncol. 2011;6:32-7.

29. Wu AH, Fontham ET, Reynolds P, Greenberg RS, Buffler P, Liff J, et al. Previous lung disease and risk of lung cancer among lifetime nonsmoking women in the United States. Am J Epidemiol. 1995;141:1023-32.

30. Liang H, Guan P, Yin Z, Li X, He Q, Zhou B. Risk of lung cancer following nonmalignant respiratory conditions among nonsmoking women living in Shenyang Northeast China. J Womens Health. 2009;18:1989-95.

31. Lin HP, Deng CY, Chou P. Diagnosis and treatment delay among pulmonary tuberculosis patients identified using the Taiwan reporting enquiry system, 2002-2006. BMC Public Health. 2009:9:55

32. Wang PD. Epidemiological trends of childhood tuberculosis in Taiwan, 1998-2005. Int J Tuberc Lung Dis. 2008;12:250-4

33. Mannino DM, Aguayo SM, Petty TL, Redd SC. Low lung function and incident lung cancer in the United States: data From the First National Health and Nutrition Examination Survey follow-up. Arch Intern Med. 2003;163:1475-80.

34. Denholm R, Schuz J, Straif K, Stucker I, Jockel KH, Brenner DR, et al. Is previous respiratory disease a risk factor for lung cancer? Am J Respir Crit Care Med. 2014:190:549-59.

35. Tsai YW, Tsai TI, Yang CL, Kuo KN. Gender differences in smoking behaviors in an Asian population. J Womens Health. 2008;17:971-8.

36. Littman AJ, Thornquist MD, White E, Jackson LA, Goodman GE, Vaughan TL. Prior lung disease and risk of lung cancer in a large prospective study. Cancer Causes Control. 2004;15:819-27.

37. Pesch B, Kendzia B, Gustavsson P, Jockel KH, Johnen G, Pohlabeln H, et al. Cigarette smoking and lung cancer-relative risk estimates for the major histological types from a pooled analysis of case-control studies. Int J Cancer. 2012;131:1210-9.

38. Freedman ND, Leitzmann MF, Hollenbeck AR, Schatzkin A, Abnet CC. Cigarette smoking and subsequent risk of lung cancer in men and women: analysis of a prospective cohort study. Lancet Oncol. 2008;9:649-56.

39. Masoli M, Fabian D, Holt S, Beasley R. The global burden of asthma: executive summary of the GINA Dissemination Committee report. Allergy. 2004:59:469-78.

40. Hwang CY, Chen YJ, Lin MW, Chen TJ, Chu SY, Chen CC, et al. Prevalence of atopic dermatitis, allergic rhinitis and asthma in Taiwan: a national study 2000 to 2007. Acta Derm Venereol. 2010;90:589-94.

41. El-Zein M, Parent ME, Ka K, Siemiatycki J, St-Pierre Y, Rousseau MC. History of asthma or eczema and cancer risk among men: a population-based 
case-control study in Montreal, Quebec. Canada Ann Allergy Asthma Immunol. 2010;104:378-84.

42. El-Zein M, Parent ME, Siemiatycki J, Rousseau MC. History of allergic diseases and lung cancer risk. Ann Allergy Asthma Immunol. 2014;112:230-6.

43. Alberti KG, Zimmet $P$, Shaw J. The metabolic syndrome-a new worldwide definition. Lancet. 2005;366:1059-62.

44. Giovannucci E, Harlan DM, Archer MC, Bergenstal RM, Gapstur SM, Habel LA, et al. Diabetes and cancer: a consensus report. Diabetes Care. 2010;33:1674-85.

Submit your next manuscript to BioMed Central and take full advantage of:

- Convenient online submission

- Thorough peer review

- No space constraints or color figure charges

- Immediate publication on acceptance

- Inclusion in PubMed, CAS, Scopus and Google Scholar

- Research which is freely available for redistribution 